\title{
PENGARUH DIAMETER NOZZLE TERHADAP DIAMETER GEL PADA PROSES GELASI EKSTERNAL KERNEL CERIA STABILIZED ZIRCONIA (CSZ)
}

\author{
Kristanti Nurwidyaningrum ${ }^{1,2}$, Wahyudi Budi Sediawan ${ }^{1}$, Indra Perdana ${ }^{1}$ \\ ${ }^{1}$ Departemen Teknik Kimia, Fakultas Teknik - Universitas Gadjah Mada \\ Jalan Grafika No. 2 Yogyakarta 55281 \\ ${ }^{2}$ Pusat Teknologi Bahan Bakar Nuklir - BATAN \\ Kawasan PUSPIPTEK Serpong Gd. 20 Tangerang Selatan, Banten 15314 \\ e-mail: kristanti@batan.go.id
}

(Naskah diterima: 16-09-2019, Naskah direvisi: 27-09-2019, Naskah disetujui: 18-10-2019)

\begin{abstract}
ABSTRAK
PENGARUH DIAMETER NOZZLE TERHADAP DIAMETER GEL PADA PROSES GELASI EKSTERNAL KERNEL CERIA STABILIZED ZIRCONIA (CSZ). Pengembangan teknologi bahan bakar nuklir diperlukan untuk dapat membuat bahan bakar sesuai dengan spesifikasi yang dipersyaratkan. Dalam produksi partikel terlapis yang memenuhi persyaratan untuk bahan bakar reaktor gas temperatur tinggi, diperlukan produksi kernel yang memenuhi kendali kualitas dan jaminan mutu dari persyaratan kernel. Salah satu persyaratan kendali kualitas untuk kernel adalah kontrol diameter. Penelitian dilakukan dengan memvariasikan diameter nozzle sehingga dapat memprediksi ukuran butiran gel yang diperoleh dari proses gelasi eksternal dengan mengkorelasikan variabel densitas umpan, viskositas umpan, tegangan muka larutan umpan dan diameter nozzle secara kuantitatif dengan metode analisis dimensi dalam bentuk bilangan tidak berdimensi. Pembuatan kernel CSZ dilakukan dengan penyiapan larutan umpan. Larutan umpan terdiri dari campuran $\mathrm{ZrO}\left(\mathrm{NO}_{3}\right)_{2} .2 \mathrm{H}_{2} \mathrm{O}$ dan $\mathrm{Ce}\left(\mathrm{NO}_{3}\right)_{3} .6 \mathrm{H}_{2} \mathrm{O}$, urea, tetrahydrofurfuryl alcohol (THFA) dan poly vinyl alcohol (PVA). Proses gelasi eksternal dilakukan dengan cara meneteskan larutan umpan ke dalam kolom gelasi yang berisi medium ammonium hidroksida sehingga terbentuk gel CSZ. Pembentukan droplet terjadi pada saat larutan umpan melewati nozzle. Diameter gel yang terbentuk dapat dihitung dengan mengkorelasikan diameter nozzle dan sifat fisis dari larutan umpan menggunakan analisis dimensi. Diameter gel hasil eksperimen diukur dengan menggunakan mikroskop optik. Diameter gel yang diperoleh dari persamaan bilangan tak berdimensi menunjukkan hasil yang tidak terlalu berbeda dengan diameter gel eksperimen, walaupun terdapat beberapa penyimpangan hasil yang diperoleh. Dari diameter gel eksperimen dan persamaan bilangan tak berdimensi menunjukkan bahwa diameter nozzle berbanding lurus dengan diameter gel.
\end{abstract}

Kata Kunci : gelasi eksternal, diameter, nozzle. 


\section{ABSTRACT}

THE EFFECT OF NOZZLE DIAMETER ON GEL DIAMETER IN EXTERNAL GELATION PROCESS OF CERIA STABILIZED ZIRCONIA (CSZ) KERNEL. In the production of coated particles that meet the requirements for high temperature gas reactor fuels, one of quality control requirements for the kernel is diameter control. The study was conducted by varying the diameter of the nozzle for predicting the size of gel diameter obtained from external gelation process by correlating variables of feed density, feed viscosity, feed solution tension and nozzle diameter quantitatively with dimensional analysis method in the form of dimensionless numbers. Fabrication of CSZ kernel was done by preparing the feed solution, which consists of a mixture of $\mathrm{ZrO}\left(\mathrm{NO}_{3}\right)_{2} \cdot 2 \mathrm{H}_{2} \mathrm{O}$ and $\mathrm{Ce}\left(\mathrm{NO}_{3}\right)_{3} \cdot 6 \mathrm{H}_{2} \mathrm{O}$, urea, tetrahydrofurfuryl alcohol (THFA) and poly vinyl alcohol (PVA). External gelation is performed by dripping sol feed solution through a nozzle into gelation column containing ammonium hydroxide solution to form CSZ gel. Droplet formation occurs when the feed solution passes by the nozzle. The diameter of the gel formed can be calculated by correlating nozzle diameter and physical properties of the feed solution using dimensional analysis. Gel diameter of the experimental results was measured using an optical microscope. The diameter of the gel obtained from the dimensionless number equation shows results that are not too different from the diameter of the experimental gel with some deviations in the data. Data of diameter measurement of experimental gel and data of calculation by dimensionless equation show that diameter of the nozzle is directly proportional to diameter of the obtained gel.

Keywords: external gelation, diameter, nozzle. 


\section{PENDAHULUAN}

Pemanfaatan energi nuklir di masa yang akan datang merupakan salah satu cara untuk pemenuhan kebutuhan energi listrik di Indonesia. Salah satu reaktor nuklir yang dipertimbangkan dibangun di Indonesia adalah reaktor suhu tinggi (RST) karena merupakan reaktor generasi IV yang aman, tanpa pelelehan bahan bakar. RST mempunyai keunggulan dari segi keamanan maupun ekonomi. Keunggulan dari segi keamanan adalah reaktor mempunyai koefisien reaktivitas suhu negatif besar jadi reaktor akan padam dengan sendirinya bila suhu naik secara berlebihan tanpa adanya intervensi dari operator. Keunggulan dari segi ekonomi adalah kemampuan reaktor sebagai sumber listrik sekaligus sumber panas (cogeneration)[1].

Konsep elemen bahan bakar yang digunakan untuk HTGR adalah elemen bahan bakar bentuk bola (pebble bed) yang digunakan di Jerman, Cina dan Afrika Selatan dan prismatik yang digunakan di Amerika Serikat dan Jepang. Perbedaan mendasar antara keduanya adalah geometri elemen bahan bakarnya. Bahan bakar bentuk pebble bed dan prismatik terdiri dari partikel terlapis dengan inti bahan bakar berupa uranium dioxide $\left(\mathrm{UO}_{2}\right)$, plutonium dioxide $\left(\mathrm{PuO}_{2}\right)$, atau campuran uranium oxycarbide (UCO) [2].

Partikel berlapis atau disebut dengan TRISO (tri-structural isotropic) yang disusun oleh kernel $\mathrm{UO}_{2}$ (pengkayaan $\mathrm{U}^{235}$ $8,2 \%)$ dengan diameter $0,05 \mathrm{~cm}$ dikelilingi oleh 4 lapisan yang terdiri atas lapisan penyangga karbon berpori (porous carbon buffer), lapisan pirokarbon bagian dalam (inner pyrolitic carbon, IPyC), lapisan silikon karbida $(\mathrm{SiC})$ dan lapisan piro karbon bagian luar (outer pyrolitic carbon, OPyC), yang terdispersi dalam matrik grafit. Sebanyak 15.000 partikel berlapis membentuk bola berdiameter $5 \mathrm{~cm}$ yang dikelilingi oleh shell grafit dengan ketebalan $0,5 \mathrm{~cm}$ dalam sebuah bahan bakar bola [3].
Penguasaan teknologi pembuatan bahan bakar untuk memenuhi persyaratan bahan bakar reaktor suhu tinggi. Dengan tujuan dari penguasaan material, proses fabrikasi dan peralatan fabrikasi, maka bahan untuk bahan bakar reaktor suhu tinggi, yaitu kernel $\mathrm{UO}_{2}$ dapat disimulasikan dengan bahan lain yang memiliki karakteristik yang sama untuk proses fabrikasi TRISO. Material yang digunakan adalah ceria stabilized zirconium (CSZ) sebagai pengganti/surrogate kernel $\mathrm{UO}_{2}$ yang akan digunakan pada proses pelapisan menjadi partikel TRISO (Tri Structural Isotropic). Hal ini karena CSZ memiliki mikrostruktur/struktur kristal yang stabil pada suhu tinggi (suhu pelapisan $1500{ }^{\circ} \mathrm{C}$ ) seperti halnya uranium dioksida dan sesuai untuk simulasi proses pelapisan kernel $\mathrm{UO}_{2}$.

Dalam produksi partikel terlapis yang memenuhi persyaratan untuk bahan bajar reaktor gas temperatur tinggi, diperlukan produksi kernel yang memenuhi kendali kualitas dan jaminan mutu dari persyaratan kernel. Salah satu persyaratan kendali kualitas untuk kernel adalah kontrol diameter. Diameter kernel berhubungan erat dengan diameter gel yang dihasilkan pada proses gelasi [4].

Penelitian tentang pembuatan gel CSZ yang meliputi parameter proses seperti konsentrasi zirkonium dan cerium sudah pernah dilakukan. Penelitian tentang pembuatan gel CSZ dengan memvariasikan diameter nozzle perlu dilakukan sehingga dapat memprediksi ukuran butiran gel yang diperoleh dari proses gelasi eksternal dengan mengkorelasikan variabel densitas umpan, viskositas umpan, tegangan muka larutan umpan dan diameter nozzle secara kuantitaif dengan metode analisis dimensi dalam bentuk bilangan tidak berdimensi. Penelitian ini diharapkan dapat memprediksi ukuran butiran gel berdasarkan diameter nozzle dan sifat fisis dari larutan umpan. 


\section{TEORI}

Analisi dimensi secara sederhana adalah perangkat matematis untuk merencanakan penelitian dengan membuat korelasi data penelitian sehingga dapat mempersingkat waktu penelitian. Dengan analisis dimensi korelasi yang relatif banyak dari variabel proses berkurang menjadi satu atau beberapa korelasi bilangan tidak berdimensi [5].

Pembuatan kernel CSZ dilakukan dengan penyiapan larutan umpan. Larutan umpan terdiri dari campuran $\mathrm{ZrO}\left(\mathrm{NO}_{3}\right)_{2} .2 \mathrm{H}_{2} \mathrm{O}$ dan $\mathrm{Ce}\left(\mathrm{NO}_{3}\right)_{3} .6 \mathrm{H}_{2} \mathrm{O}$, urea, tetrahydrofurfuryl alcohol (THFA) dan poly vinyl alcohol (PVA). Proses gelasi eksternal dilakukan dengan cara meneteskan larutan umpan ke dalam kolom gelasi yang berisi medium ammonium hidroksida sehingga terbentuk gel CSZ. Pembentukan droplet terjadi pada saat larutan umpan melewati nozzle.

Secara teori diameter gel yang dihasilkan dipengaruhi oleh diameter nozzle, kecepatan alir umpan, frekuensi vibrasi, densitas, serta viskositas umpan. Pada saat larutan umpan menetes melewati nozzle dan tetesan tersebut dilewatkan lapisan udara maka pada waktu tersebut terjadi tetesan sol bentuk bola sebagai hasil tegangan muka. Microsphere (bulatan sol) ini selanjutnya melewati medium ammonium hidroksida dan bereaksi membentuk gel CSZ. Pada proses gelasi, diameter gel yang dihasilkan akan sangat tergantung dengan diameter nozzle, tekanan/kecepatan alir dan tinggi kolom gelasi yang digunakan. Kesempurnaan bentuk dan ukuran kernel terjadi pada saat penetesan melewati nozzle/orifice menuju media/fluida yang tidak dapat campur. Dimana butiran sol akan mempertahankan bentuk kebolaanya pada saat keluar nozzle karena sol mempunyai viskositas dan tegangan muka tertentu [6].

Menurut Matthews [7], tetesan sol terbentuk karena keseimbangan gaya berat tetes yang jatuh dari nozzle dan tahanan oleh nozzle. Ketika tetes sol jatuh gaya berat sol ditambah kekuatan kinetik dari fluida yang mengalir keluar dari lubang nozzle melebihi gaya yang bekerja menahan tetes jatuh pada orifice (tegangan antar muka ditambah gaya tekan keatas dari media). Volume tetes (untuk pada aliran yang rendah) dapat dinyatakan dengan persamaan (1) untuk memprediksi diameter gel berdasarkan diameter nozzle [8]

$V s=\frac{F \pi \gamma D_{0}}{g \Delta \rho}$

Keterangan :

$\mathrm{Vs}=$ volume tetes

$\mathrm{Y}=$ tegangan muka

Do = diameter nozzle

$\mathrm{g}=$ gravitasi

$\Delta \rho=$ beda densitas antara dua fluida

$\mathrm{F}=$ faktor koreksi tetes tinggal di nozzle

Diameter gel/volume tetesan adalah merupakan hasil gel yang diameternya tergantung dari diameter nozzle dan kecepatan alir cairannya. Bila menginginkan diameter kernel besar maka kita harus memperbesar Do (diameter nozzle) dan tekanan atau kecepatan alir cairan begitu pula sebaliknya.

Ukuran gel yang terbentuk pada saat proses gelasi dipengaruhi oleh diameter nozzle dan sifat fisis dari larutan umpan. Dengan asumsi tersebut maka diameter butiran gel yang terbentuk dihubungkan dengan variabel proses yaitu diameter nozzle, gravitasi, viskositas dan berat jenis larutan umpan. Secara matematis, diameter butiran gel sebagai fungsi parameter proses dituliskan sebagai berikut :

$D p=f(\Delta P, d n, \sigma, g, \rho, \mu)$

Keterangan :

$\mathrm{Dp}=$ Diameter gel $(\mathrm{m})$

$\Delta P=$ Pressure Drop $\left(\mathrm{N} / \mathrm{m}^{2}\right)$

$\mathrm{dn}=$ Diameter nozzle $(\mathrm{m})$

$\mathrm{Y}=$ Tegangan muka larutan umpan $(\mathrm{N} / \mathrm{m})$

$\mathrm{g}=$ Percepatan gravitasi $\left(\mathrm{m} / \mathrm{s}^{2}\right)$

$\rho=$ Densitas larutan umpan $\left(\mathrm{kg} / \mathrm{m}^{3}\right)$

$\mu \quad=$ Viskositas larutan umpan $(\mathrm{kg} / \mathrm{m} . \mathrm{s})$ 
Dengan menggunakan analisis dimensi, persamaan (2) dituliskan sebagai persamaan tak berdimensi.

$$
\begin{gathered}
D p=K(\Delta P)^{C 1}(d n)^{C 2}(\gamma)^{C 3}(g)^{C 4}(\rho)^{C 5}(\mu)^{C 6}(3) \\
{[L]=\left[\frac{M}{L^{2}}\right]^{C 1}[L]^{C 2}\left[\frac{M}{T^{2}}\right]^{C 3}\left[\frac{L}{T^{2}}\right]^{C 4}\left[\frac{M}{L^{3}}\right]^{C 5}\left[\frac{M}{L T}\right]^{C 6}(4)}
\end{gathered}
$$

Dari persamaan (4) diperoleh hubungan pangkat sebagai berikut:

Dimensi $\mathrm{L} \quad 1=-\mathrm{C}_{1}+\mathrm{C}_{2}+\mathrm{C}_{4}-3 \mathrm{C}_{5}-\mathrm{C}_{6}$

Dimensi M $0=\mathrm{C}_{1}+\mathrm{C}_{3}+\mathrm{C}_{5}+\mathrm{C}_{6}$

Dimensi T $0=-2 \mathrm{C}_{1}-2 \mathrm{C}_{3}-2 \mathrm{C}_{4}-\mathrm{C}_{6}$

Dalam persamaan (4) ada 6 bilangan tidak diketahui dengan 3 persamaan, sehingga 3 bilangan tidak diketahui tetap ada untuk menyatakan 3 bilangan lainnya.

$\mathrm{C}_{6}=2 \mathrm{C}_{4}-2 \mathrm{C}_{5}$

$\mathrm{C}_{2}=1+\mathrm{C}_{1}+\mathrm{C}_{4}+\mathrm{C}_{5}$

$\mathrm{C}_{3}=-\mathrm{C}_{1}-2 \mathrm{C}_{4}+\mathrm{C}_{5}$

Persamaan (3) dapat dituliskan:

$$
\begin{aligned}
D p= & K(\Delta P)^{C 1}(d n)^{(1+\mathrm{C} 1+\mathrm{C} 4+\mathrm{C} 5)}(\gamma)^{(-\mathrm{C} 1-2 \mathrm{C} 4+\mathrm{C} 5)} \\
& (g)^{C 4}(\rho)^{C 5}(\mu)^{(2 \mathrm{C} 4-2 \mathrm{C} 5)} \\
\frac{D p}{d n}= & K \cdot\left(\frac{\Delta P \cdot d n}{\sigma}\right)^{C 1} \cdot\left(\frac{d n \cdot g \cdot \mu^{2}}{\sigma^{2}}\right)^{C 4} \cdot\left(\frac{\rho \cdot d n \cdot \sigma}{\mu^{2}}\right)^{C 5}
\end{aligned}
$$

Pada penelitian ini, variabel yang divariasikan hanya diameter nozzle sedangkan sifat fisis (physical properties) dari larutan umpan tidak divariasikan, maka persamaan (12) disederhanakan menjadi:

$\frac{D p}{d n}=K \cdot\left(\frac{\Delta P \cdot d n}{\gamma}\right)^{C 1} \cdot\left(\frac{d n \cdot g \cdot \mu^{2}}{\gamma^{2}}\right)^{C 7} \cdot\left(\frac{\rho \cdot \gamma^{3}}{g \cdot \mu^{4}}\right)^{C 5}$

Nilai dari $\left(\frac{\rho . \gamma^{3}}{g \cdot \mu^{4}}\right)^{C 5}$ tetap, sehingga dapat digabungkan nilainya dengan $\mathrm{K}$ menjadi :

$\frac{D p}{d n}=K 1 \cdot\left(\frac{\Delta P \cdot d n}{\gamma}\right)^{C 1} \cdot\left(\frac{d n \cdot g \cdot \mu^{2}}{\gamma^{2}}\right)^{C 7}$

Nilai dari $\mathrm{K}_{1}, \mathrm{C}_{1}$ dan $\mathrm{C}_{7}$ dievaluasi dengan data percobaan sehingga didapatkan persamaan bilangan tak berdimensi.

\section{METODOLOGI}

\section{Bahan}

Bahan yang digunakan pada penelitian ini adalah $\mathrm{ZrO}\left(\mathrm{NO}_{3}\right)_{2} .2 \mathrm{H}_{2} \mathrm{O}$ dan $\mathrm{Ce}\left(\mathrm{NO}_{3}\right)_{3} .6 \mathrm{H}_{2} \mathrm{O}$, urea, tetrahydrofurfuryl alcohol (THFA), poly vinyl alcohol (PVA), air bebas mineral (ABM), $\mathrm{NH}_{4} \mathrm{OH}$.

\section{Penyiapan Larutan Umpan}

Larutan umpan dibuat dengan melarutkan $\mathrm{ZrO}\left(\mathrm{NO}_{3}\right)_{2} \cdot 2 \mathrm{H}_{2} \mathrm{O}$ dan $\mathrm{Ce}\left(\mathrm{NO}_{3}\right)_{3} .6 \mathrm{H}_{2} \mathrm{O}$ dalam air bebas mineral (ABM) dengan perbandingan mol $\mathrm{Ce} / \mathrm{Zr}$ $=12 \%$. Urea ditambahkan ke dalam campuran $\mathrm{ZrO}\left(\mathrm{NO}_{3}\right)_{2} \cdot 2 \mathrm{H}_{2} \mathrm{O}$ dan $\mathrm{Ce}\left(\mathrm{NO}_{3}\right)_{3} \cdot 6 \mathrm{H}_{2} \mathrm{O}$ pada suhu $85^{\circ} \mathrm{C}$ selama 1 jam. Selama pemanasan, urea akan terdekomposisi dan membentuk mixed sol metal nitrat. Pada mixed sol metal nitrat ditambahkan zat aditif berupa PVA dan THFA untuk mengatur viskositas dari larutan umpan. Viskositas dari larutan umpan diukur dengan menggunakan viskosimeter. Densitas larutan umpan diukur dengan menggunakan piknometer.

\section{Proses Gelasi}

Peralatan gelasi yang digunakan pada penelitian ini ditunjukkan pada Gambar 1, larutan umpan dialirkan dengan cara ditekan menggunakan kompresor. Larutan umpan diteteskan melewati nozzle yang berukuran 0,8 $\mathrm{mm}, 1 \mathrm{~mm}$ dan $1,2 \mathrm{~mm}$ ke dalam kolom gelasi yang berisi larutan ammonium hidroksida $\left(\mathrm{NH}_{4} \mathrm{OH}\right)$. Gel yang dihasilkan dari proses gelasi diukur diameternya menggunakan mikroskop optik.

\section{Analisis Data}

Bentuk persamaan dp/dn diubah ke dalam bentuk log $(\mathrm{Dp} / \mathrm{dn})=\log \mathrm{K}_{1}+\mathrm{C}_{1} \log$ $(\Delta \mathrm{P} \cdot \mathrm{dn} / \mathrm{\gamma})+\mathrm{C}_{7} \log \left(\mathrm{dn} \cdot \mathrm{g} \cdot \mu^{2} / \mathrm{\gamma}^{2}\right)$, sehingga dengan menggunakan regresi linear konstanta $\mathrm{K}_{1}, \mathrm{C}_{1}$ dan $\mathrm{C}_{7}$ dapat diketahui dengan memasukkan data eksperimen. Diameter gel hasil persamaan bilangan tak berdimensi diverifikasi dengan diameter gel eksperimen. 


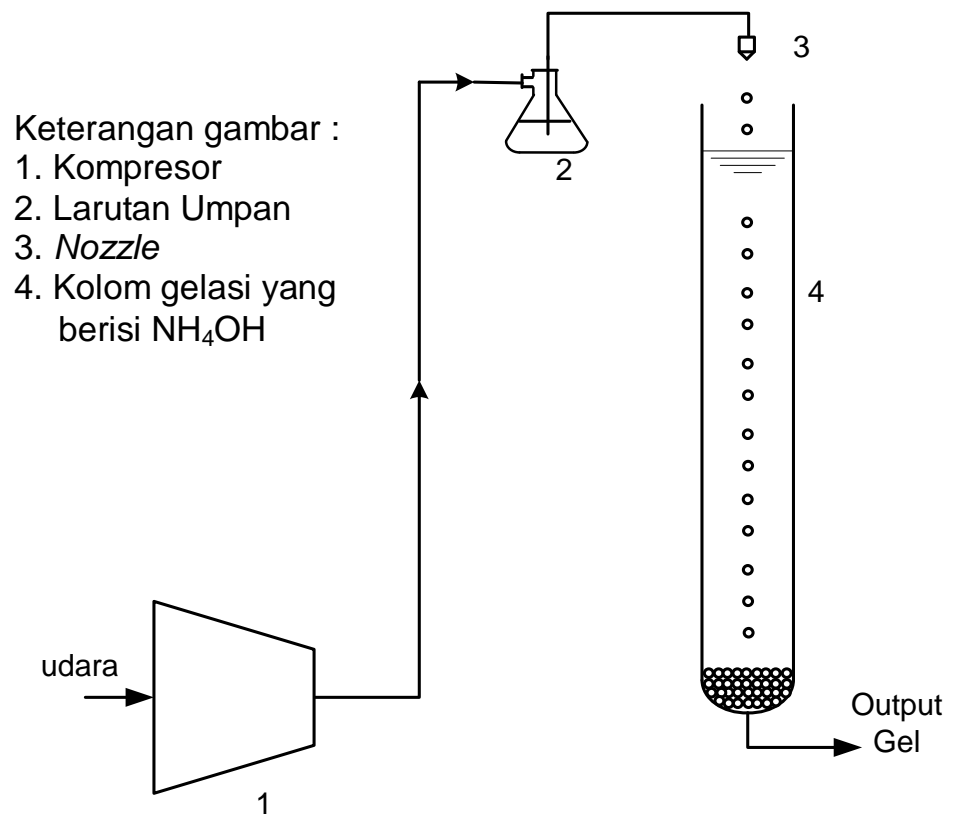

Gambar 1. Rangkaian alat proses gelasi

\section{HASIL DAN PEMBAHASAN}

Dari hasil penelitian diperoleh data pada tabel 1. Untuk menghitung nilai $\mathrm{K}_{1}, \mathrm{C}_{1}$ dan $\mathrm{C}_{7}$ dibutuhkan nilai dari diameter nozzle yang divariasikan dari eksperimen, pressure drop, tegangan muka larutan umpan, viskositas larutan umpan. Nilai dari tegangan muka larutan umpan diukur dengan menggunakan metode pipa kapiler.

$$
\gamma=\frac{1}{2} r \rho g h
$$

\section{Keterangan :}

$\mathrm{Y}=$ tegangan permukaan, $\mathrm{N} / \mathrm{m}$

$r \quad=$ jari-jari pipa kapiler, $m$

$\rho=$ densitas larutan umpan, $\mathrm{kg} / \mathrm{m}^{3}$

$\mathrm{h}=$ kenaikan pipa kapiler, $\mathrm{m}$

$\mathrm{g}=$ percepatan gravitasi, $\mathrm{m} / \mathrm{s}^{2}$

Diameter gel yang dihasilkan pada proes gelasi dapat dilihat pada Tabel 1 . Tabel 1 menunjukkan bahwa diameter nozzle yang digunakan pada penelitian ini adalah $0,8 \mathrm{~mm}, 1 \mathrm{~mm}$ dan $1,2 \mathrm{~mm}$ untuk tinggi kolom gelasi 50,75 dan $100 \mathrm{~cm}$. Pada Tabel 1 dapat dilihat bahwa semakin besar diameter nozzle yang digunakan maka semakin besar diameter gel yang diperoleh.
Nilai dari variabel $\mathrm{K}_{1}, \mathrm{C}_{1}$ dan $\mathrm{C}_{7}$ pada persamaan (14) diperoleh dengan memasukkan data eksperimen. Dengan melakukan regresi linier, maka diperoleh nilai dari konstanta $\mathrm{K}_{1}, \mathrm{C}_{1}$ dan $\mathrm{C}_{7}$ yang dapat dilihat pada persamaan (16).

$\frac{D p}{d n}=7,0648 \cdot\left(\frac{\Delta P \cdot d n}{\gamma}\right)^{-0,161} \cdot\left(\frac{d n \cdot g \cdot \mu^{2}}{\gamma^{2}}\right)^{-0,0116}$

Gambar 2 menunjukkan hubungan diameter gel eksperimen dengan diameter gel persamaan bilangan tak berdimensi. Secara grafis dapat terlihat bahwa nilai diameter gel persamaan bilangan tak berdimensi mendekati nilai dari diameter gel eksperimen, walaupun terdapat beberapa penyimpangan. Rerata kesalahan yang diperoleh adalah sebesar 0,1143.

Gambar 3 merupakan hubungan diameter nozzle dengan diameter gel yang diperoleh baik dari hasil eksperimen dan persamaan bilangan tak berdimensi. Pada Gambar 3, dapat dilihat bahwa semakin besar diameter nozzle yang digunakan maka diameter gel eksperimen yang diperoleh juga semakin besar. Hasil yang sama juga diperoleh oleh diameter gel persamaan bilangan tak berdimensi, dari 
Gambar 3 menunjukkan kecenderungan yang sama yaitu semakin besar diameter nozzle maka diameter gel yang dihasilkan semakin besar. Hal ini sesuai dengan persamaan (1) yang dikatakan oleh Matthews bahwa diameter gel/volume tetes berbanding lurus dengan diameter nozzle.
Adanya variasi hasil diameter gel eksperimen yang diperoleh bisa terjadi karena berkurangnya volume larutan umpan dalam labu sehingga pada saat pembentukan droplet mempengaruhi tekanan atau kecepatan aliran umpan sehingga menyebabkan variasi diameter gel.

Tabel 1. Data proses gelasi eksternal dan diameter gel eksperimen

\begin{tabular}{|c|c|c|c|c|c|}
\hline Sampel & $\begin{array}{l}\text { Tinggi Kolom } \\
\text { Gelasi } \\
\text { (cm) }\end{array}$ & $\begin{array}{c}\text { Diameter } \\
\text { Nozzle } \\
(\mathrm{mm})\end{array}$ & $\begin{array}{l}\text { Konsentrasi } \\
\text { Medium } \\
\text { (N) }\end{array}$ & $\begin{array}{l}\text { Viskositas } \\
\text { Umpan } \\
\text { (kg/m.s) }\end{array}$ & $\begin{array}{c}\text { Diameter Gel } \\
(\mathrm{mm})\end{array}$ \\
\hline Sampel 1 & 50 & 0,80 & 6 & 0,04 & 1,7061 \\
\hline Sampel 2 & 50 & 0,80 & 7 & 0,04 & 1,7600 \\
\hline Sampel 3 & 50 & 0,80 & 8 & 0,04 & 1,7810 \\
\hline Sampel 4 & 50 & 1,00 & 6 & 0,04 & 1,9590 \\
\hline Sampel 5 & 50 & 1,00 & 7 & 0,04 & 1,9832 \\
\hline Sampel 6 & 50 & 1,00 & 8 & 0,04 & 2,0980 \\
\hline Sampel 7 & 50 & 1,20 & 6 & 0,04 & 2,2810 \\
\hline Sampel 8 & 50 & 1,20 & 7 & 0,04 & 2,3210 \\
\hline Sampel 9 & 50 & 1,20 & 8 & 0,04 & 2,4200 \\
\hline Sampel 10 & 75 & 0,80 & 6 & 0,04 & 1,7560 \\
\hline Sampel 11 & 75 & 0,80 & 7 & 0,04 & 1,8140 \\
\hline Sampel 12 & 75 & 0,80 & 8 & 0,04 & 1,8680 \\
\hline Sampel 13 & 75 & 1,00 & 6 & 0,04 & 2,0460 \\
\hline Sampel 14 & 75 & 1,00 & 7 & 0,04 & 2,1660 \\
\hline Sampel 15 & 75 & 1,00 & 8 & 0,04 & 2,1680 \\
\hline Sampel 16 & 75 & 1,20 & 6 & 0,04 & 2,3510 \\
\hline Sampel 17 & 75 & 1,20 & 7 & 0,04 & 2,4040 \\
\hline Sampel 18 & 75 & 1,20 & 8 & 0,04 & 2,4240 \\
\hline Sampel 19 & 100 & 0,80 & 6 & 0,04 & 1,8050 \\
\hline Sampel 20 & 100 & 0,80 & 7 & 0,04 & 1,8300 \\
\hline Sampel 21 & 100 & 0,80 & 8 & 0,04 & 1,9080 \\
\hline Sampel 22 & 100 & 1,00 & 6 & 0,04 & 2,1000 \\
\hline Sampel 23 & 100 & 1,00 & 7 & 0,04 & 2,1700 \\
\hline Sampel 24 & 100 & 1,00 & 8 & 0,04 & 2,2600 \\
\hline Sampel 25 & 100 & 1,20 & 6 & 0,04 & 2,7940 \\
\hline Sampel 26 & 100 & 1,20 & 7 & 0,04 & 2,9020 \\
\hline Sampel 27 & 100 & 1,20 & 8 & 0,04 & 2,9380 \\
\hline
\end{tabular}




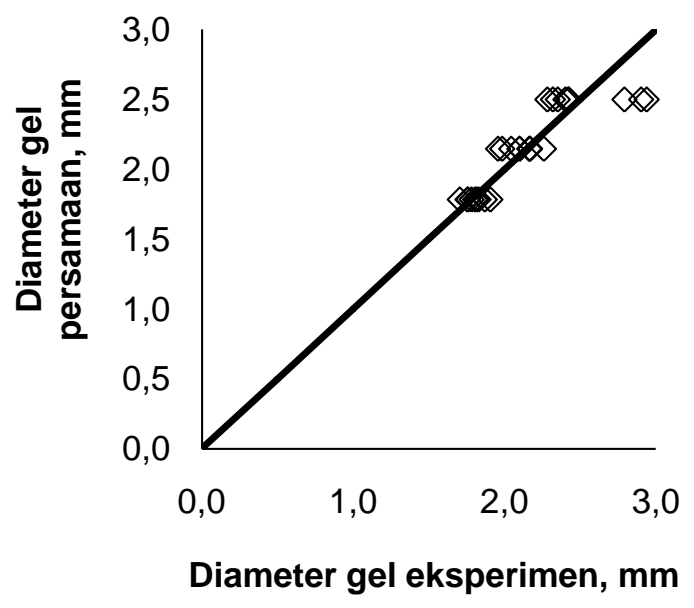

Gambar 2. Hubungan diameter gel eksperimen dengan diameter gel persamaan

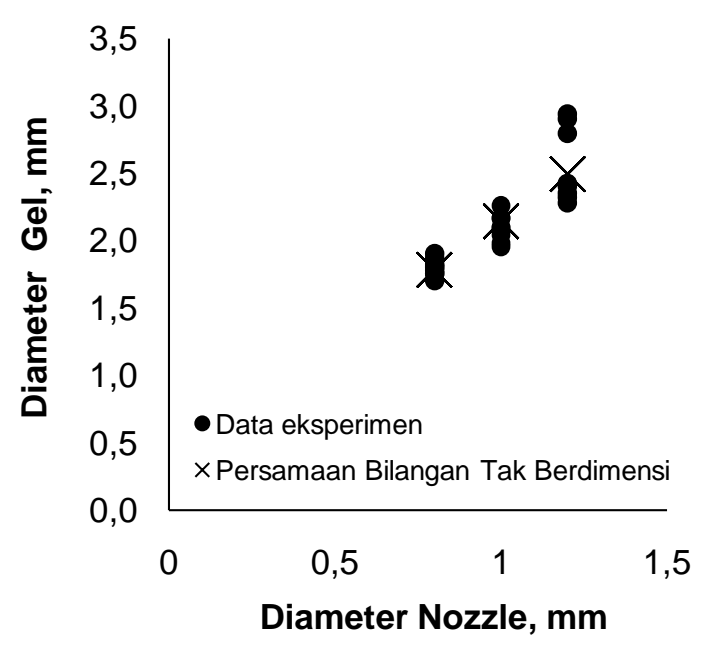

$\begin{array}{ccr}\text { Gambar 3. Hubungan } & \text { diameter } & \text { nozzle } \\ \text { dengan } & \text { diameter } & \text { gel } \\ \text { eksperimen } & & \end{array}$

\section{SIMPULAN}

Mekanisme pembentukan droplet atau butiran pada dasarnya adalah peristiwa fisika. Diameter nozzle dan sifat fisis dari larutan umpan berpengaruh terhadap ukuran droplet yang terbentuk. Persamaan diameter gel dapat dituliskan sebagai hubungan dari diameter nozzle dan sifat fisis larutan umpan menjadi bilangan tak berdimensi yang secara matematis adalah:

$$
\frac{D p}{d n}=7,0648 \cdot\left(\frac{\Delta P \cdot d n}{\gamma}\right)^{-0,161} \cdot\left(\frac{d n \cdot g \cdot \mu^{2}}{\gamma^{2}}\right)^{-0,0116}
$$

Diameter gel persamaan bilangan tak berdimensi menunjukkan hasil yang tidak jauh berbeda dengan diameter gel eksperimen dengan rerata kesalahan 0,1143. Dari hasil yang diperoleh secara eksperimen maupun persamaan bilangan tak berdimensi menunjukkan bahwa diameter nozzle berbanding lurus dengan diameter gel. Hal ini sesuai dengan persamaan yang diberikan oleh Matthews.

\section{UCAPAN TERIMA KASIH}

Penulis mengucapkan terima kasih kepada pihak-pihak yang telah membantu penelitian sehingga dapat menyusun karya tulis ilmiah ini.

\section{DAFTAR PUSTAKA}

[1] S. M. Goldberg, R. Rosner, "Nuclear reactors: generation to generation", American Academy of Arts and Sciences, 2011.

[2] IAEA,IAEA-TECDOC-CD-1645, 2010.

[3] Zuhair, "Studi pemodelan dan perhitungan transport monte carlo dalam teras HTR pebbel bed," Jurnal Penelitian Fisika dan Aplikasinya, vol. 2, no. 2, hal. 1-9, 2012.

[4] E. Yusnitha, Sarjono, S. R. Susilowati, W. Dewayatna dan W. B. Sediawan, "Simulasi diameter gel basah pada fabrikasi kernel yttriastabilized zirconia menggunakan alat gel-casting," Jurnal IImiah Daur Bahan Bakar Nuklir Urania, vol. 24, no. 3, hal. 143-154, 2018.

[5] Handbook for Chemical Engineers, McGraw Hill Book Co., New York, 1999.

[6] Sutarni, Triyono, S.R. Susilowati, S. Mudjiman, T. Mageti dan B. Warsito, "Pembuatan dan uji fungsi reaktor gelasi sistem presolidifikasi di fasa gas," Prosiding Pertemuan dan Presentasi Ilmiah - Penelitian Dasar IImu Pengetahuan dan Teknologi Nuklir, 2014, hal. 13-21. 
[7] Matthews, R.B., and Swanson, L., "Fabrication of large $(\mathrm{Th}, \mathrm{U}) \mathrm{O}_{2}$ microspheres," The $80^{\text {th }}$ Annual Meeting of the American Ceramic Society, 1979, pp. 223-227.

[8] Sukarsono dan M. Rahmawati, "Pengaruh viskositas sol dan presolidifikasi pada gelasi eksternal dalam pembuatan gel ammonium diuranat menggunakan surrogate cerium," Jurnal IImiah Daur Bahan Bakar Nuklir Urania, vol. 23, no. 2, hal. 69-86, 2017.

[9] Kristanti Nurwidyaningrum, "Proses gelasi eksternal pada pembuatan kernel ceria stabilized zirconia (CSZ) sebagai surrogate kernel $\mathrm{UO}_{2}$ pada bahan bakar reaktor suhu tinggi," M.S. thesis, Universitas Gadjah Mada, Yogyakarta, Indonesia, 2019. 
